\title{
From general research questions to specific answers: Underspecificity as a source of uncertainty in biological conservation
}

\section{Susana Suárez-Seoane1, *}

s.seoane@unileon.es

\section{Jose Manuel Álvarez-Martínezż}

\section{Carlos Palacín 3 @}

Juan Carlos Alonso3

aáÁrea de Ecología, Departamento de Biodiversidad y Gestión Ambiental, Facultad de Ciencias Biológicas y Ambientales, Universidad de León, Campus de Vegazana s/n, 24071 León, Spain

릍nvironmental Hydraulics Institute "IH Cantabria”, Universidad de Cantabria, Parque Científico y Tecnológico de Cantabria, C/Isabel Torres, 15, 39011 Santander, Spain

${ }^{33}$ Museo Nacional de Ciencias Naturales (CSIC), José Gutiérrez Abascal 2, 28006 Madrid, Spain

${ }^{*}$ Corresponding author.

\section{Abstract}

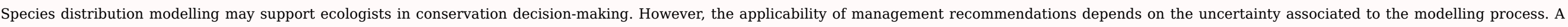

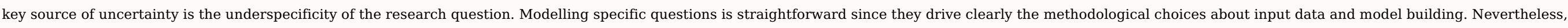

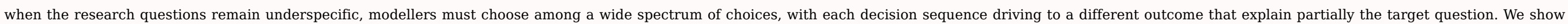

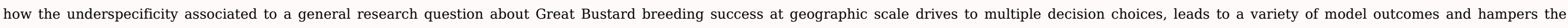

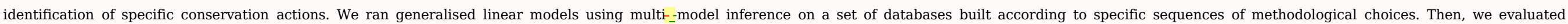

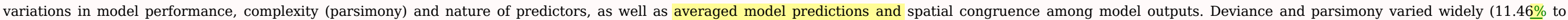

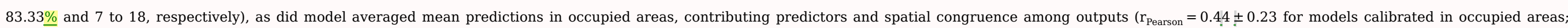

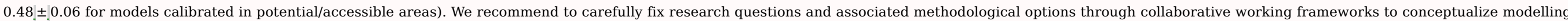
approaches and, thus, to mitigate problems arising from underspecificity and other forms of uncertainty in conservation applications.

Keywords: Breeding success; Breeding site selection; Great Bustard; Species distribution modelling

\subsection{Introduction}

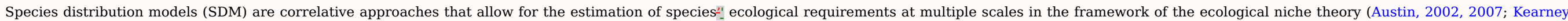

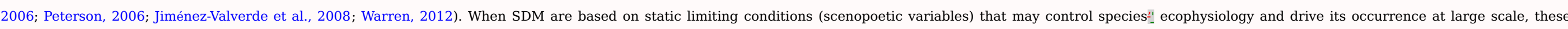

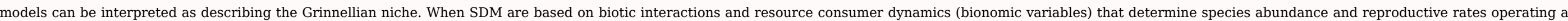
more detailed scales, they can be interpreted as describing the Eltonian niche (Soberon, 2007; Tingley et al., 2009; Peterson et al., 2012; Alvarez-Martínez et al., 2015)

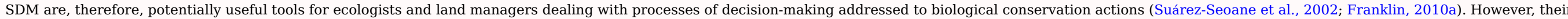

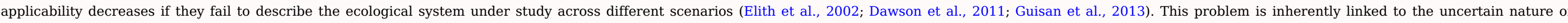

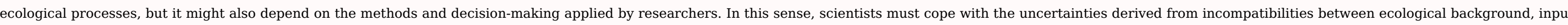

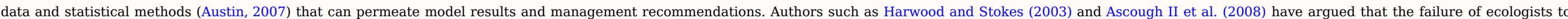




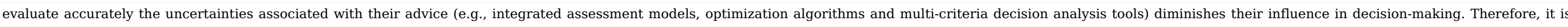

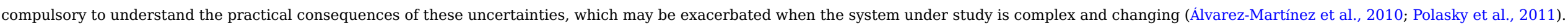

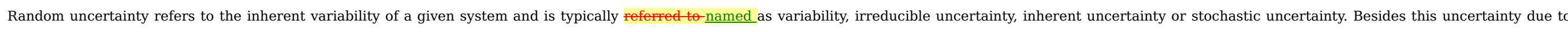

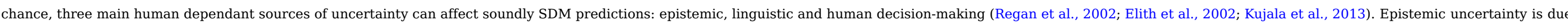

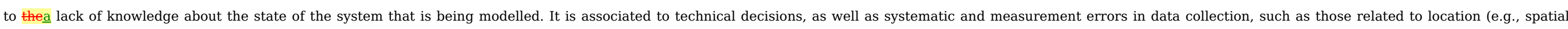

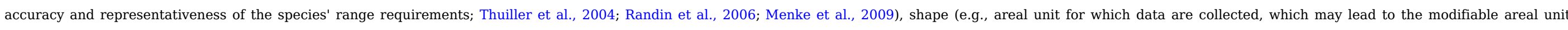

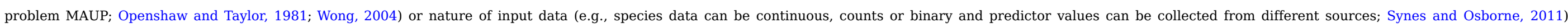

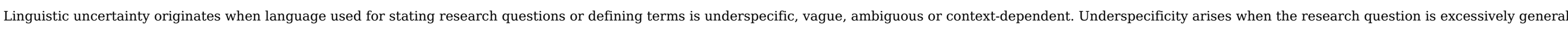

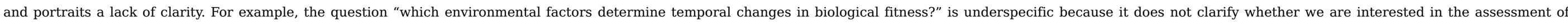

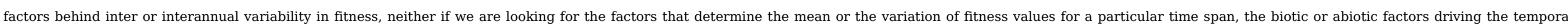

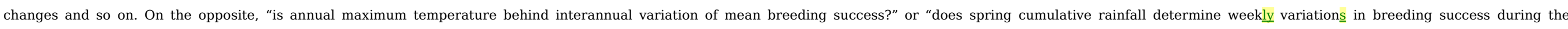

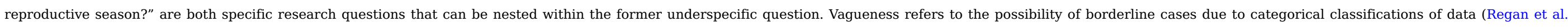

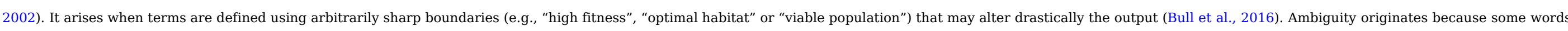

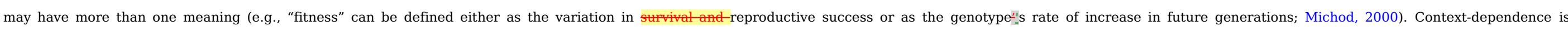

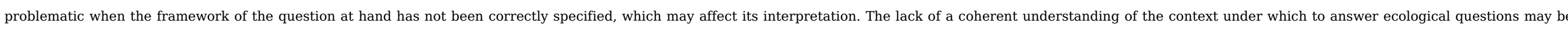

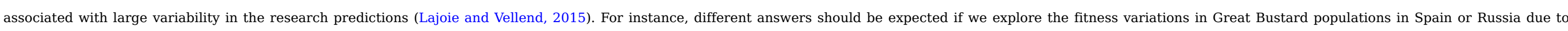

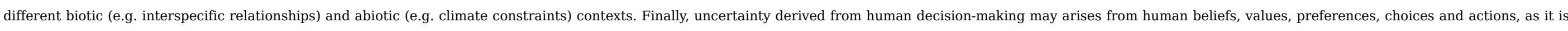

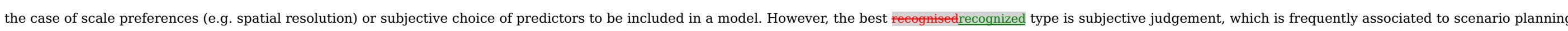

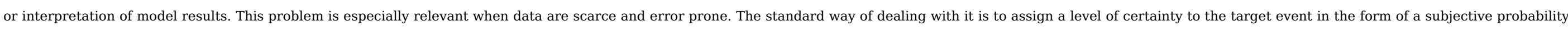

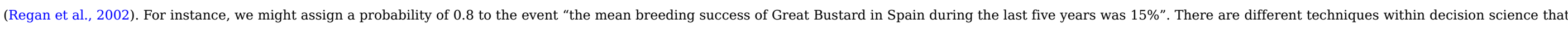

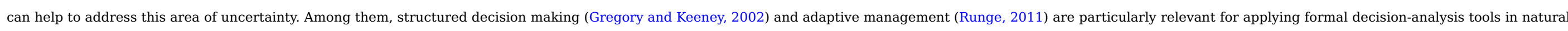
resource management decisions.

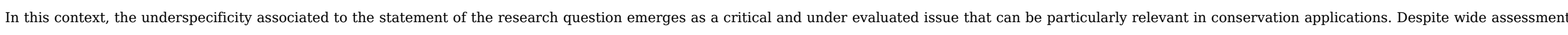

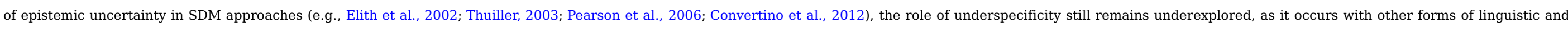

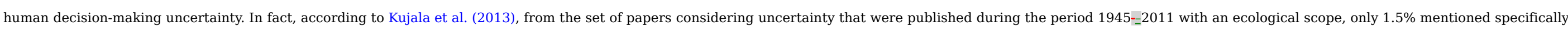

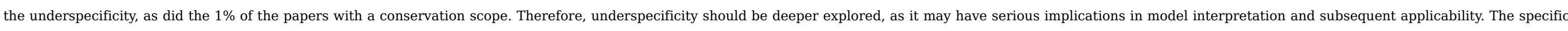

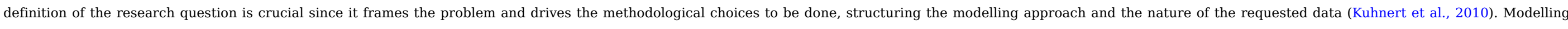

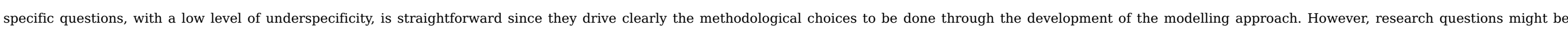

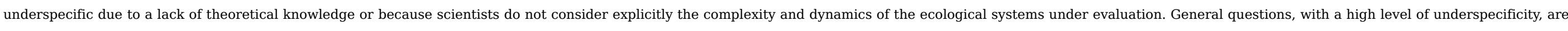

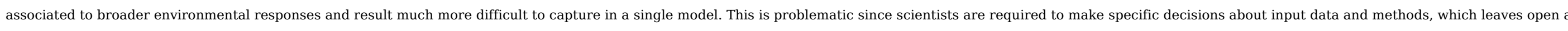

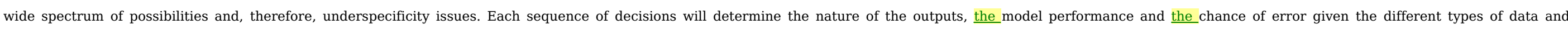

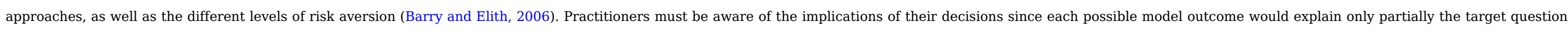
with a wide array of different outputs.

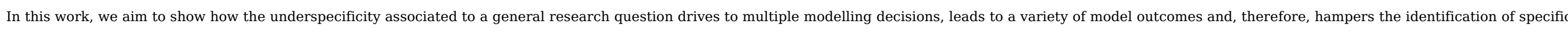

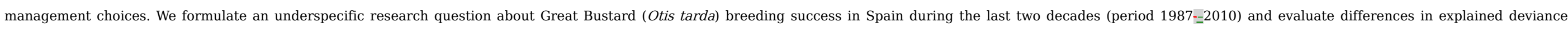

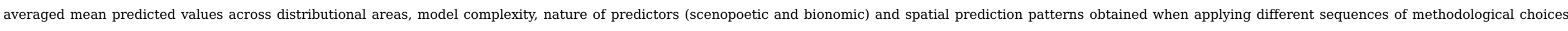

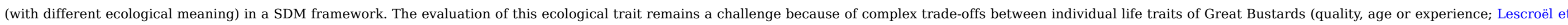




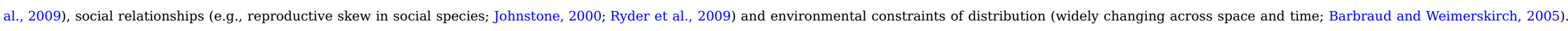

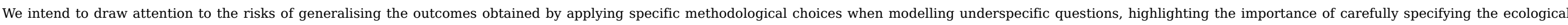
question that one aims to disentangle.

\subsection{Methods}

\subsubsection{Data on Great Bustard breeding success in Spain}

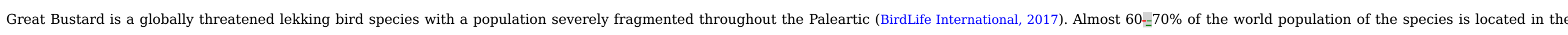

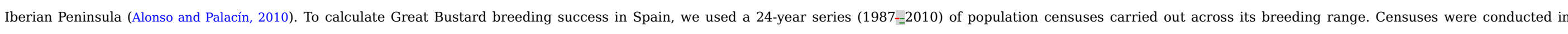

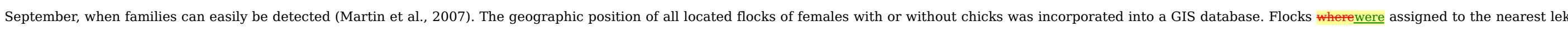

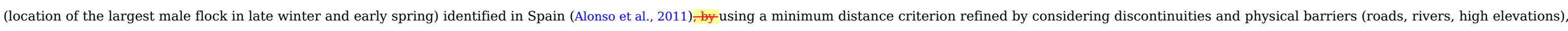

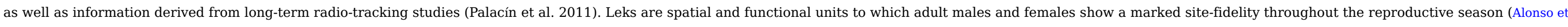

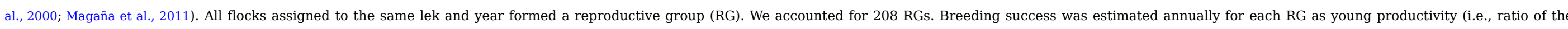

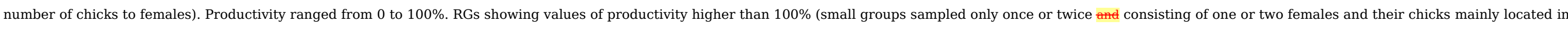

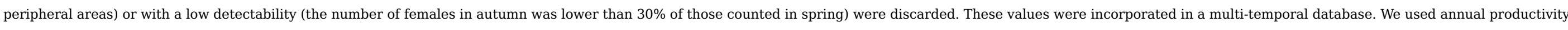

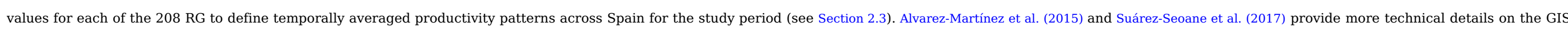
database building.

\subsubsection{Environmental variables}

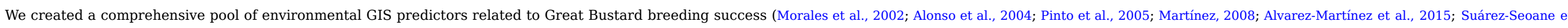

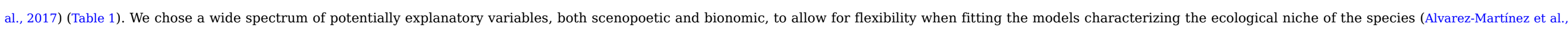

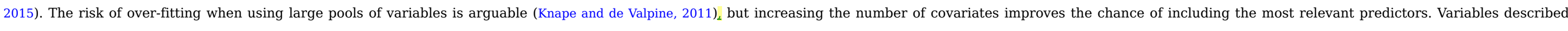

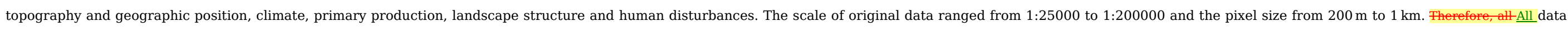
were rescaled to the same spatial resolution, matching the broader pixel size of $1 \mathrm{~km}$.

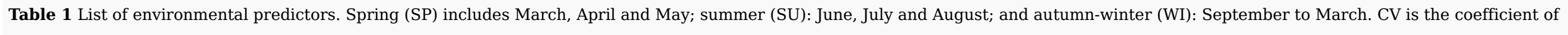
variation $=[(S D / \bar{x}) * 100]$, where $\mathrm{SD}$ is the standard deviation.

alt-text: Table 1

\begin{tabular}{|c|c|c|c|c|c|c|}
\hline & Variable & Code & Units & Source & $\begin{array}{c}\text { Pixel } \\
(\mathrm{m})\end{array}$ & Scale \\
\hline \multirow{7}{*}{$\begin{array}{l}\text { Topography, geographic } \\
\text { position }\end{array}$} & $\begin{array}{l}\text { Southness (south-north downslope, ranging from }+1 \text { to - } \\
=1 \text { ) }\end{array}$ & $\begin{array}{l}\text { SOUTH } \\
\text { EAST }\end{array}$ & Adimensional & \multirow{4}{*}{ DEM 25_m (CNIG, 2012) } & \multirow{4}{*}{200} & \multirow{4}{*}{$1: 200000$} \\
\hline & Eastness (east-west downslope, ranging from +1 to $-=1$ ) & EAST & Adimensional & & & \\
\hline & $\begin{array}{l}\text { Curvature (second derivative of the surface; }-=1 \text { in } \\
\text { valleys, }+1 \text { in ridges) }\end{array}$ & CURV & Adimensional & & & \\
\hline & Roughness (standard deviation of the slope) & RUG & Degrees & & & \\
\hline & Mean slope & SLOSP & $0=-255$ & \multirow{2}{*}{ GIS database of agricultural plots (SIGPAC, 2012) } & \multirow{2}{*}{1000} & \multirow{2}{*}{$1: 10000$} \\
\hline & $\mathrm{CV}$ of slope & SLOSPcv & $0-=255$ & & & \\
\hline & Longitude & LONG & $\mathrm{m}$ & ArcGIS desktop 10.5 (ESRI, 2016) & 100 & $1: 50000$ \\
\hline
\end{tabular}


Mean temperature: thermal amplitude of spring (range)

TMErSP

${ }^{\circ} \mathrm{C}$

Minimum temperature: summer (mean)

TMImSU

Minimum temperature: autumn-winter (CV)

TMIvWI Dimensionless

Minimum temperature: annual thermal amplitude

(range)

Minimum temperature: thermal amplitude of summer (range)

TMIrAN

${ }^{\circ} \mathrm{C}$

Maximum temperature: summer (CV)

TMIrSU

${ }^{\circ} \mathrm{C}$

Maximum temperature: autumn-winter (CV)

TMAvSU Dimensionless

Climatic Map of the Iberian Peninsula -(Ninyerola et al., 2005, 2007) (Original data: monthly, period 1950--99)

TMAvWI Dimensionless

Maximum temperature: thermal amplitude of summer (range)

Rainfall: spring (mean)

TMArSU $\quad{ }^{\circ} \mathrm{C}$

Rainfall: spring (CV)

PPmSP

Rainfall: autumn-winter (CV)

PPvSP

$\mathrm{mm}$

Dimensionless

Rainfall amplitude: annual (range)

PPvWI

Rainfall amplitude: spring (range)

PPrAN

Dimensionless

$\mathrm{mm}$

PPrSP $\mathrm{mm}$

Absolute evapotranspiration (AE): autumn-winter (mean)

Absolute evapotranspiration: summer CV

AEVPmWI

Absolute evapotranspiration: autumn-winter CV

Relative evapotranspiration (soil moisture): autumn-

winter (mean)

AEVPvWI Dimensionless

Relative evapotranspiration (soil moisture): annual (CV)

REVPmWI [\%]

Relative evapotranspiration (soil moisture): autumn-

REVPvAN

Dimensionless

winter (CV)

REVPvW

Dimensionless

Net Radiation: spring (CV)

NRADvSP Dimensionless

METEOSAT (Original data: 10-daily basis, period 1988--2010)

Net Radiation: summer (CV)

NRADvSU Dimensionless

Maximum difference in annual mean absolute

evapotranspiration

MD_EmAN $[(\mathrm{mm}) /$ day $]$

Maximum difference in annual mean net radiation

MD NmAN $\mathrm{W} / \mathrm{m}^{2}$

Maximum difference in annual CV relative

evapotranspiration

MD RvAN Dimensionless

Maximum difference in annual CV net radiation

MD NvAN Dimensionless

NDVI: spring (mean)

NDVImSP Dimensionless

NDVI: summer (mean)

NDVImSU Dimensionless

NDVIvAN Dimensionless 


\begin{tabular}{|c|c|c|c|c|c|c|}
\hline & NDVI: spring (CV) & NDVIvSP & Dimensionless & & & \\
\hline & NDVI: summer (CV) & NDVIvSU & Dimensionless & & & \\
\hline & NDVI: autumn-winter (CV) & NDVIvWI & Dimensionless & & & \\
\hline \multirow{9}{*}{ Landscape structure } & $\begin{array}{l}\text { Plot Fragmentation Index (no. plots divided by their } \\
\text { average area) }\end{array}$ & PFI & $\%$ & \multirow{4}{*}{ GIS database of agricultural plots (SIGPAC, 2012) } & \multirow{4}{*}{\multicolumn{2}{|c|}{ 1000-_1:10000 }} \\
\hline & $\mathrm{CV}$ of plot perimeter & PERIMv & Dimensionless & & & \\
\hline & Sum of plot perimeter & PERIMsum & $\mathrm{km}$ & & & \\
\hline & Maximum perimeter of plots & PERIMmax & $\mathrm{km}$ & & & \\
\hline & Arable land (\% occupation) & ARLAND & $\%$ & \multirow{5}{*}{ Land Cover Information System of Spain (SIOSE, 2012) } & \multirow{5}{*}{200} & \multirow{5}{*}{$1: 25000$} \\
\hline & Other crops (\% occupation): olive and vineyards & OLIVIN2 & $\%$ & & & \\
\hline & Irrigated lands (\% occupation) & IRRIG & $\%$ & & & \\
\hline & Dry cereal crops (\% occupation) & CEREAL & $\%$ & & & \\
\hline & Dry olives and vineyards (\% occupation) & OLIVIN & $\%$ & & & \\
\hline \multirow{6}{*}{ Human disturbances } & $\begin{array}{l}\text { Distance to paved roads of communication (roads and } \\
\text { highways) }\end{array}$ & DISTRO & $\mathrm{m}$ & BCN200 (CNIG, 2012) & 200 & $1: 200000$ \\
\hline & $\begin{array}{l}\text { Distance to human infrastructures (villages, cities, urban } \\
\text { sprawl, industries) }\end{array}$ & DISTED & $\mathrm{m}$ & SIOSE (2012) & 200 & $1: 25000$ \\
\hline & Human footprint & HUMFP & Dimensionless & NASA (2012) & 1000 & $1: 200000$ \\
\hline & $\begin{array}{l}\text { Distance to SCI (Sites of Community Importance; } \\
\text { "Natura 2000" Network) }\end{array}$ & DISTSCI & $\mathrm{m}$ & \multirow{3}{*}{ “Natura 2000” Ecological Network (MAGRAMA, 2012) } & \multirow{3}{*}{200} & \multirow{3}{*}{$1: 200000$} \\
\hline & $\begin{array}{l}\text { Distance to SPAs (Special Protection Areas; “Natura } \\
2000 \text { ” Network) }\end{array}$ & DISTSPA & $\mathrm{m}$ & & & \\
\hline & $\begin{array}{l}\text { Distance to IBAs (Important Bird Areas; BirdLife } \\
\text { International) }\end{array}$ & DISTIBA & $\mathrm{m}$ & & & \\
\hline
\end{tabular}

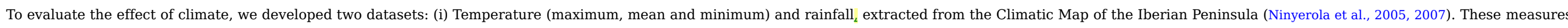

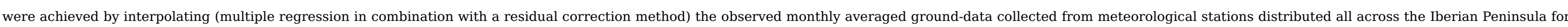

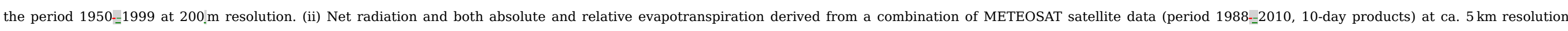

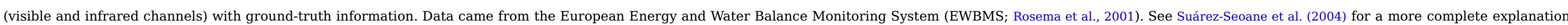

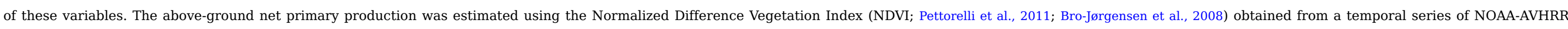

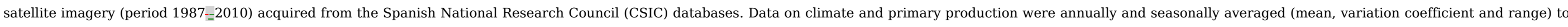

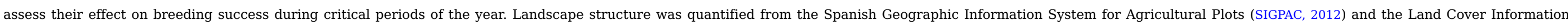

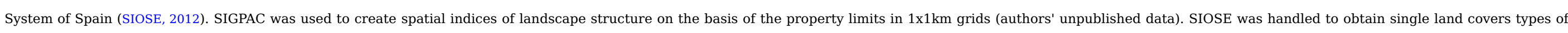

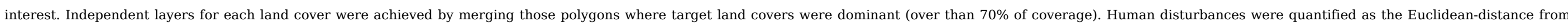
each pixel to the nearest town, road or other infrastructure; human footprint (NASA, 2012); and, land protection status. All GIS analyses were done in ArcGIS 10.5 (ESRI, 2016).

\subsubsection{Methodological choices and databases}

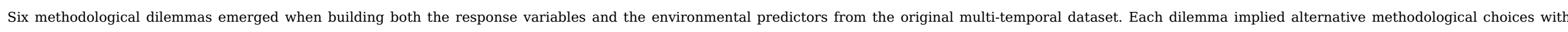

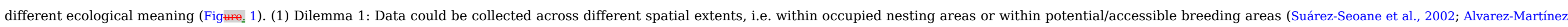




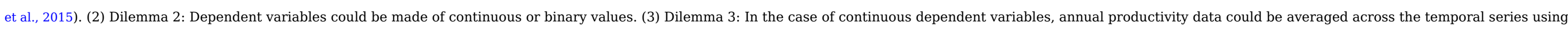

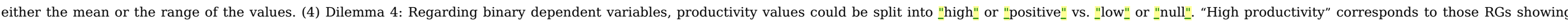

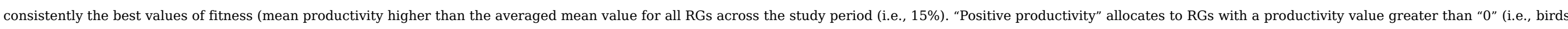

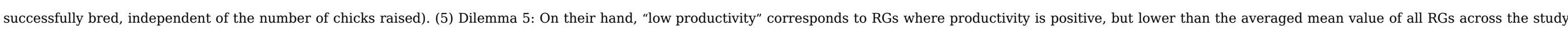

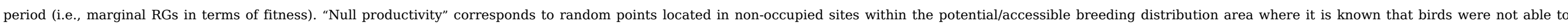

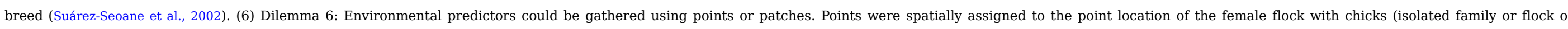

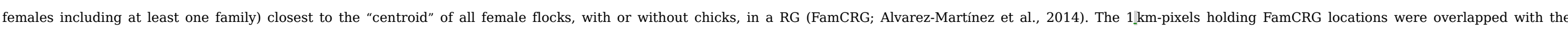

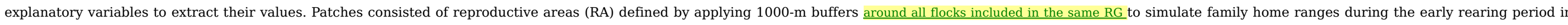

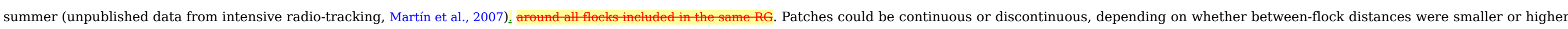

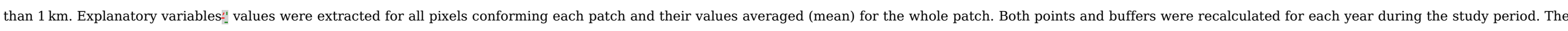

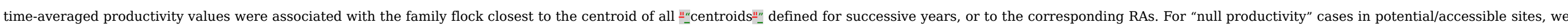

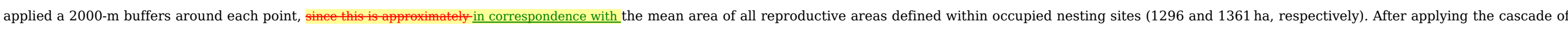
methodological dilemmas and choices, we obtained 10 databases (Figme. 2) that were used for model calibration.

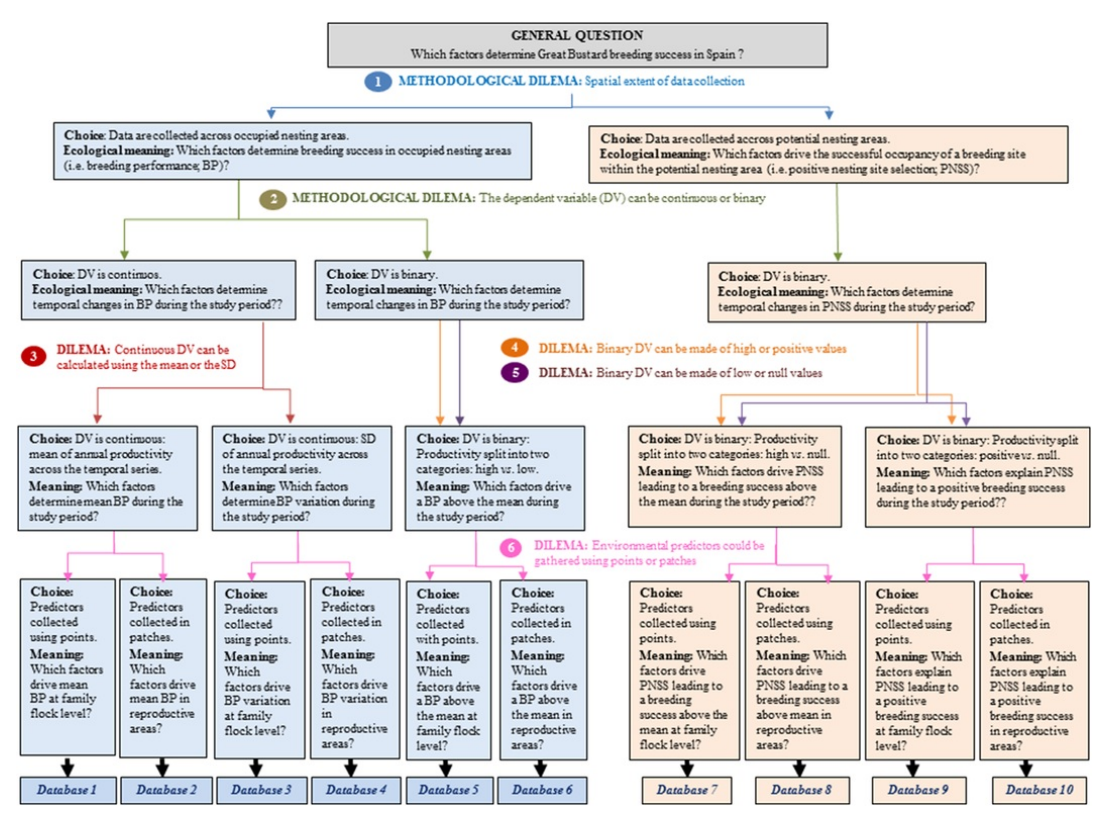

Figure 1.Fiq. 1 Methodological dilemmas and specific choices (each with a different ecological meaning) emerging when modelling the underspecific research question related to Great Bustard breeding success. alt-text: Fig. 1 


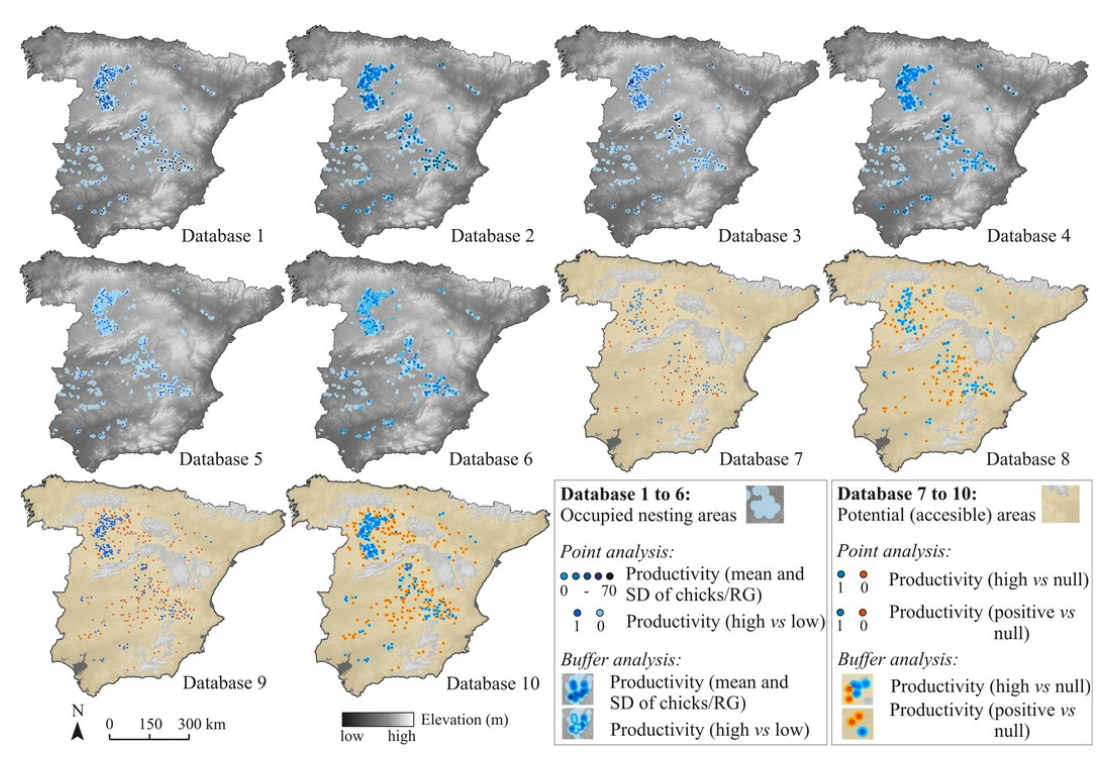

Figure 2.Fig. 2 Spatial distribution of dependent and independent variables included in each of the 10 databases. They were obtained by applying different methodological dilemmas and choices. alt-text: Fig. 2

\subsubsection{SDM building: multicollinearity, step-AIC, multi-model inference and spatial outputs}

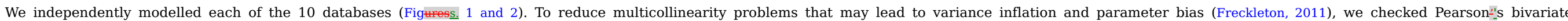

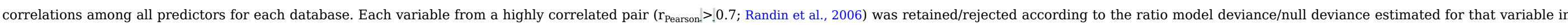

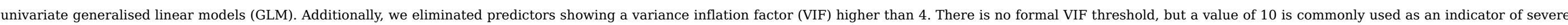
multicolinearity (Neter et al., 1990; Graham, 2003; Zuur et al., 2010).

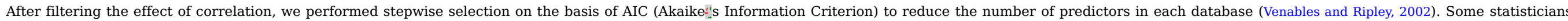

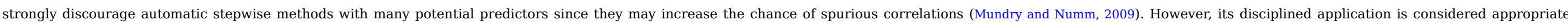
when data exploration is clearly separated from hypothesis testing (Pinheiro and Bates, 2000; Zuur et al., 2010).

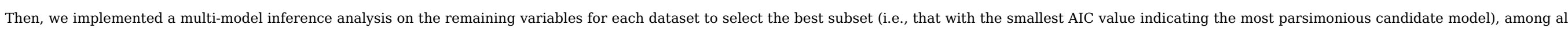

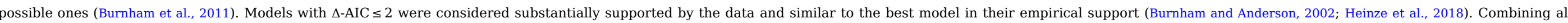

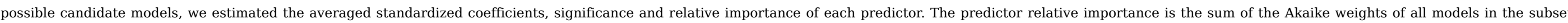

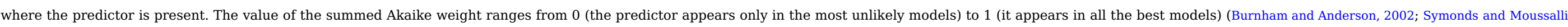

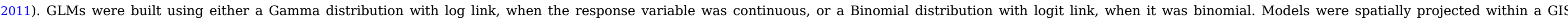
framework to generate maps of breeding habitat suitability.

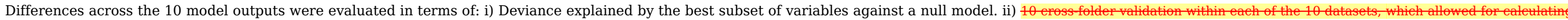

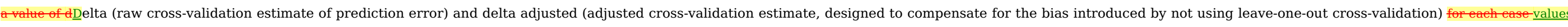

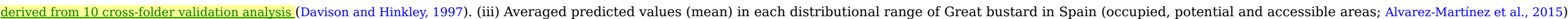

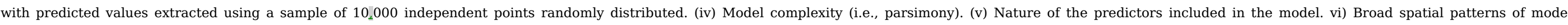

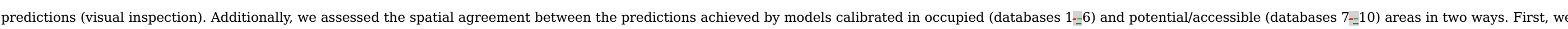




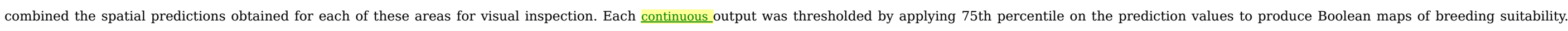

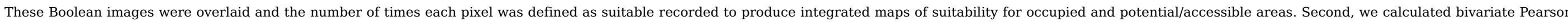

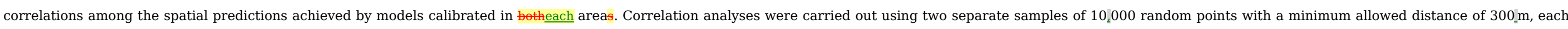
distributed across either occupied or potential/accessible area.

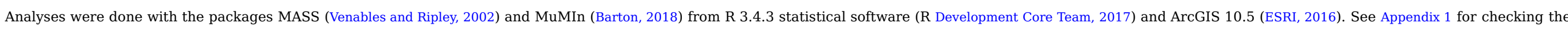
R script.

\section{3 Results}

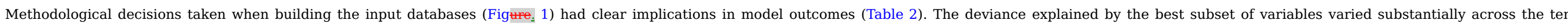

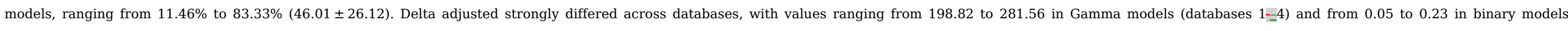

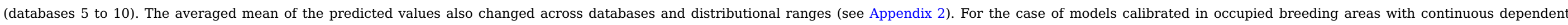

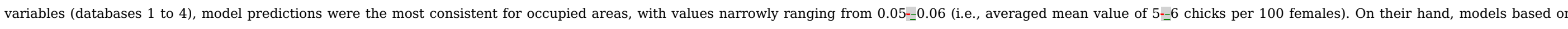

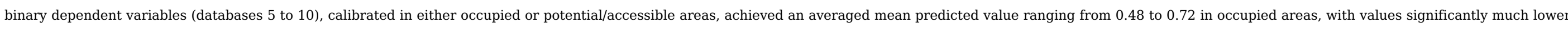

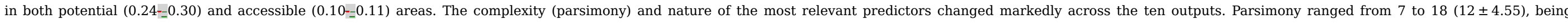

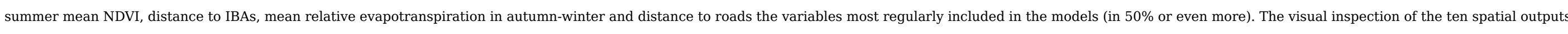

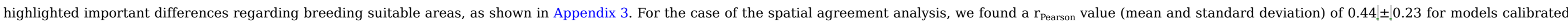
in occupied areas and 0.48 \pm 0.06 for models calibrated in potential/accessible areas (Figwre. 3 and Appendix 4).

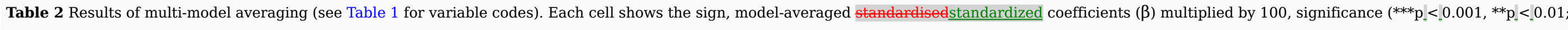

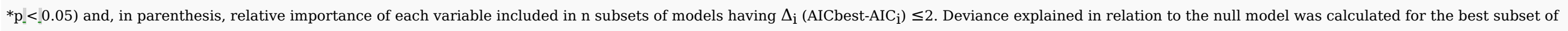
variables, as well as delta and delta adjusted for 10 cross-folder validation models (10-cv). 


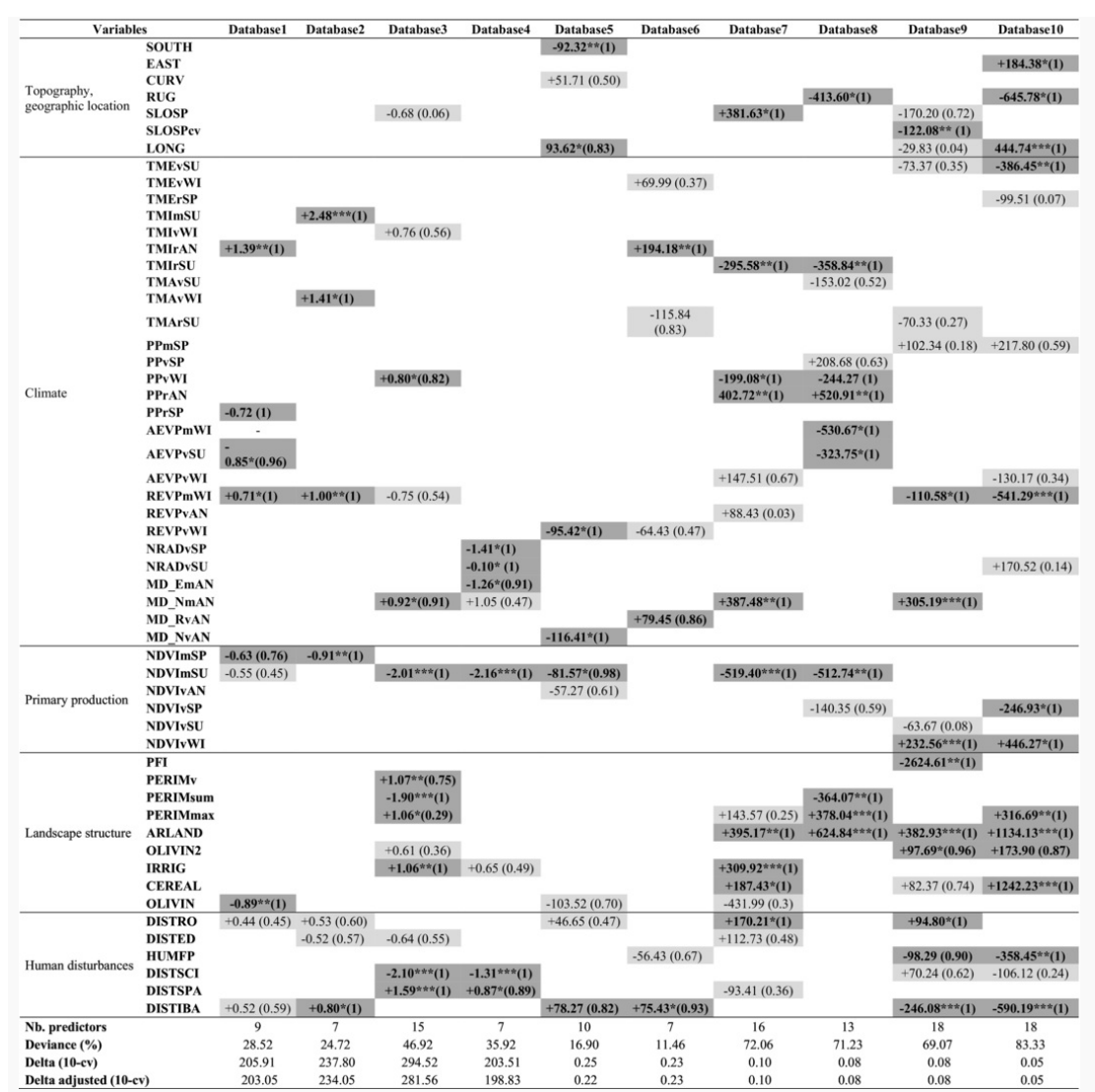

alt-text: Table 2

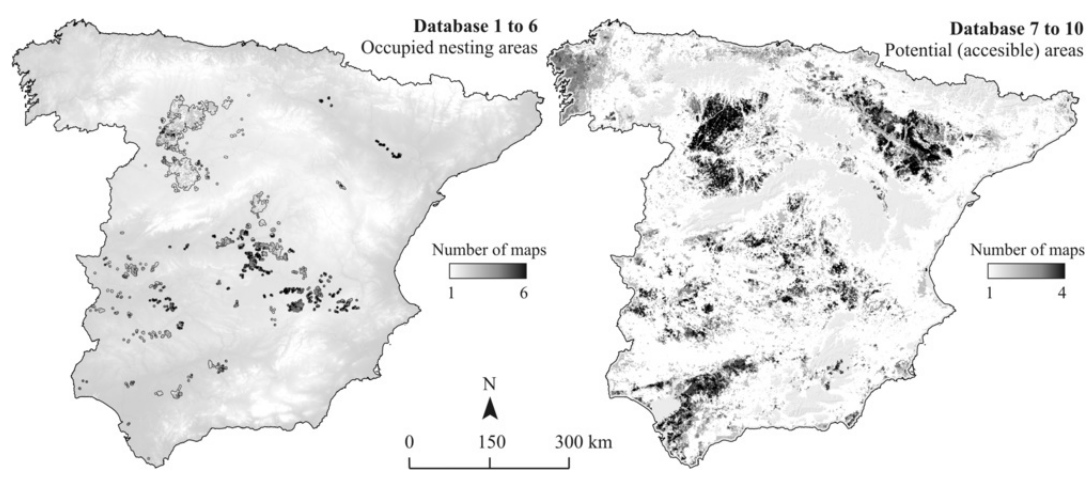

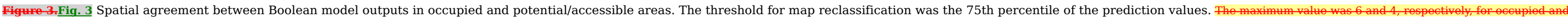
potontartacessible areas.

alt-text: Fig. 3

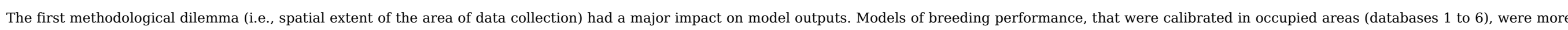




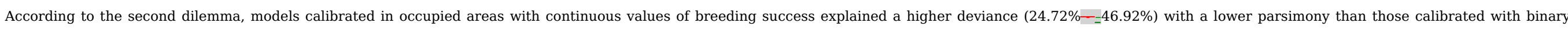
values (11.46\%-16.90\%). In potential/accessible areas, where all models were calibrated with binary dependent variables, explained deviance was the highest, with values over 69.07\%.

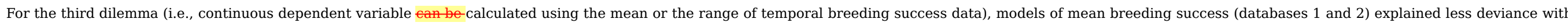

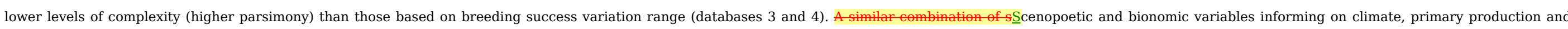
human disturbances played an equivalent role when modelling the two pairs of databases, but topography and landscape structure were more relevant when modelling the variation of breeding success.

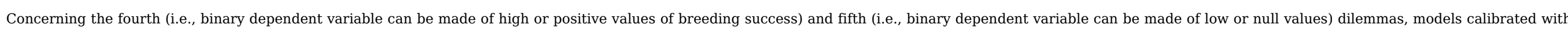

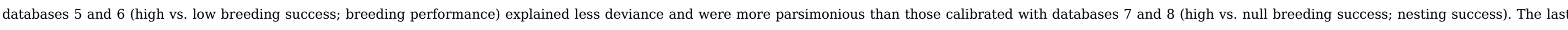

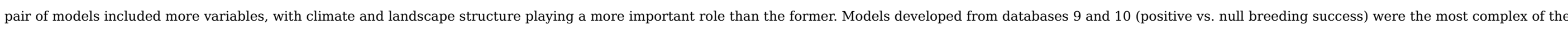
whole set (lowest parsimony), showed a strong effect of all predictor families and explained the highest values of deviance.

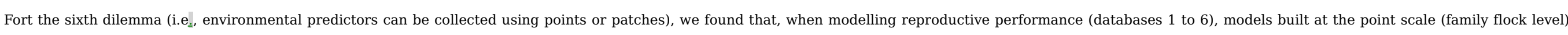

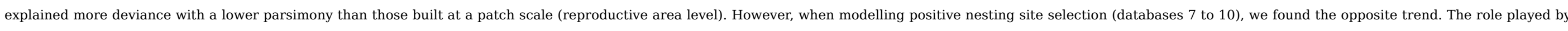
scenopoetic variables, as topography and landscape structure was more important at the point scale.

\section{4. $\underline{4}$ Discussion}

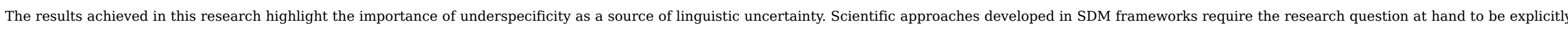

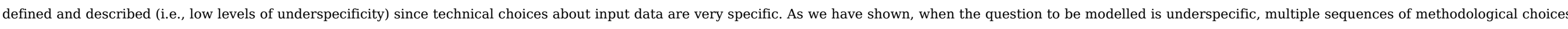

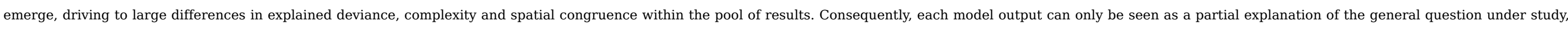

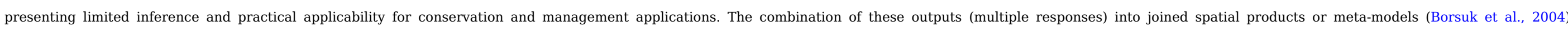
emphasized the need of considering explicitly the uncertainties associated to methodological decisions for a complete understanding of the process under study (Uusitalo et al., 2015).

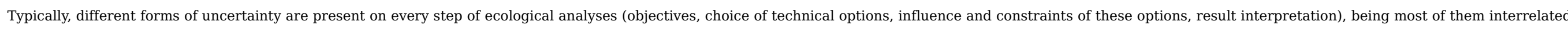

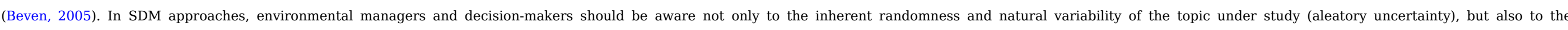

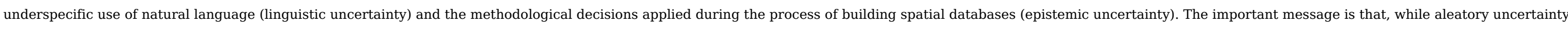

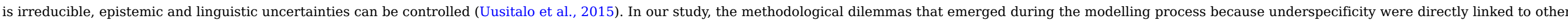
forms of linguistic and epistemic uncertainty.

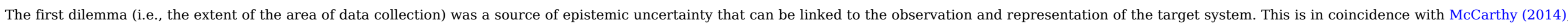

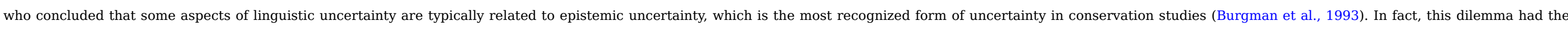

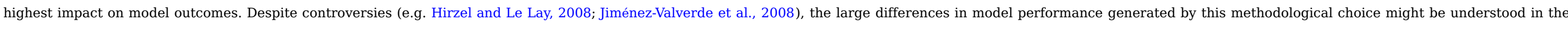

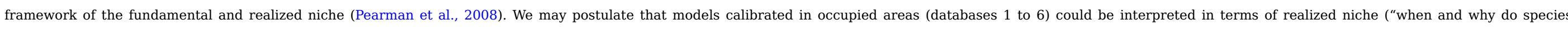

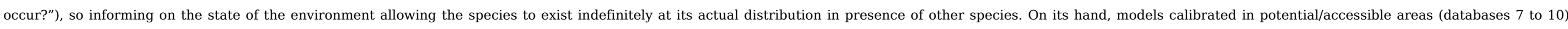

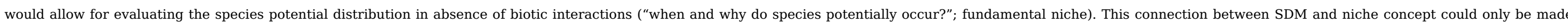

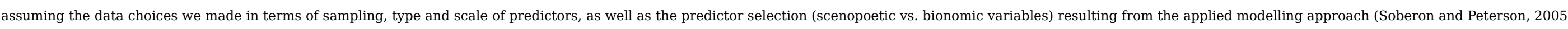

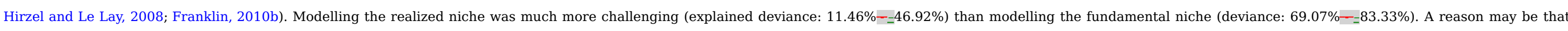

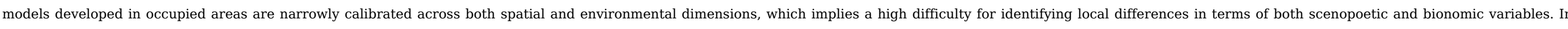

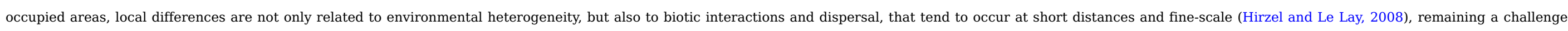




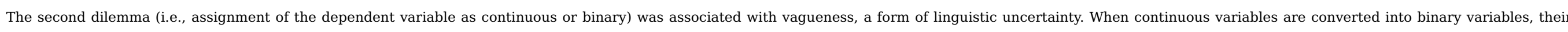

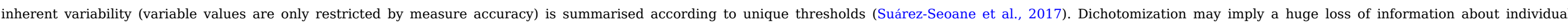

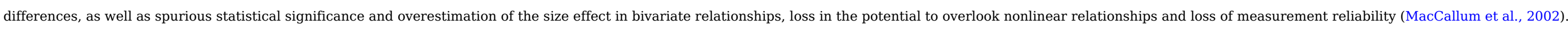

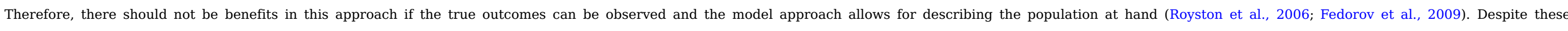

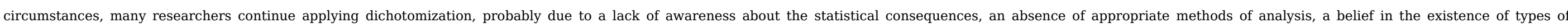

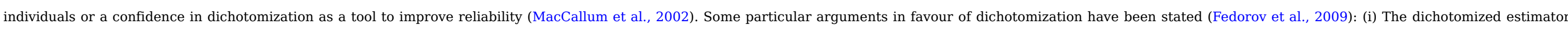

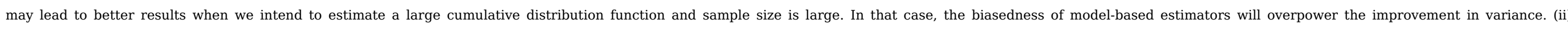

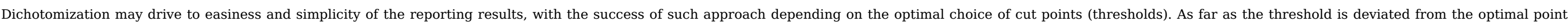

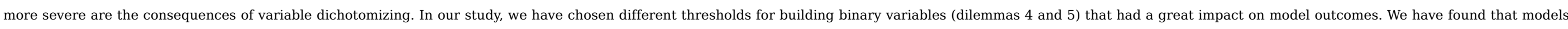

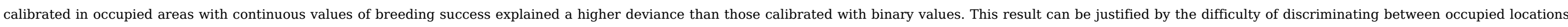

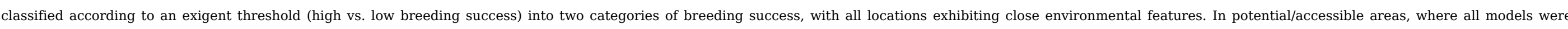

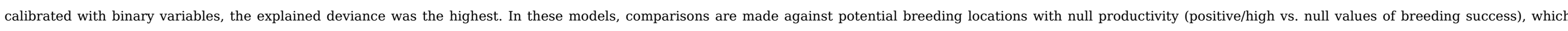
implies sharp environmental differences among locations that are easier to capture in the models.

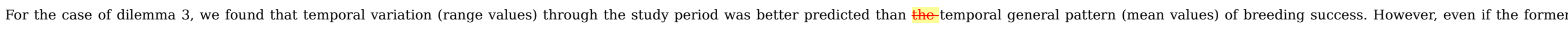

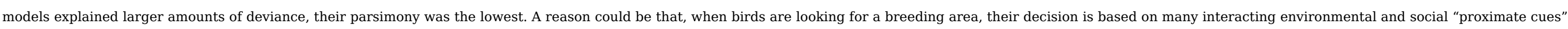

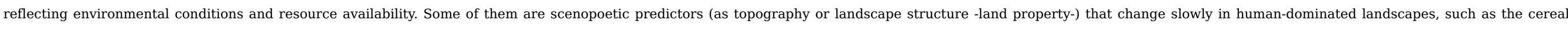

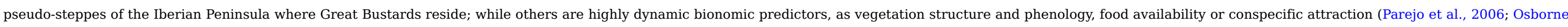
et al., 2007; Rieucau, 2011).

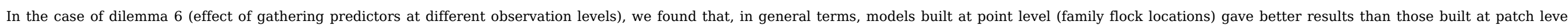

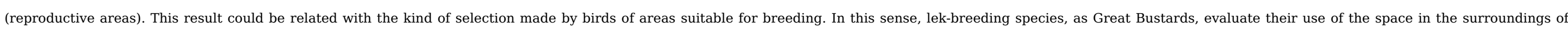

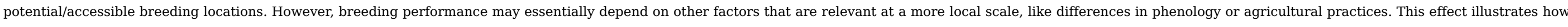
understanding landscape patterns and processes may depend on the level at which observations are made (Suárez-Seoane and Baudry, 2002).

\section{5. $\underline{5}$ Recommendations and implications for conservation}

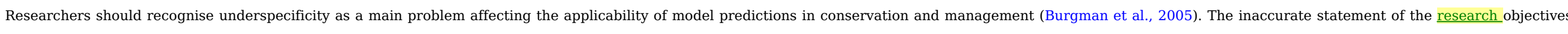

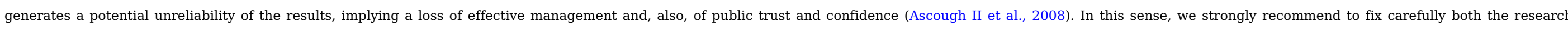

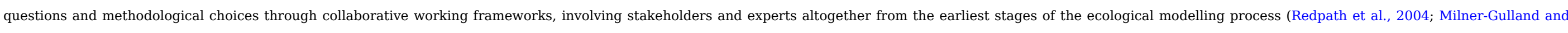

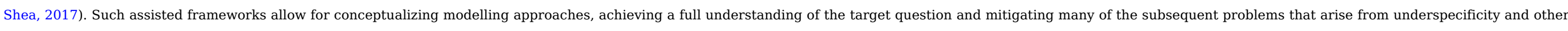

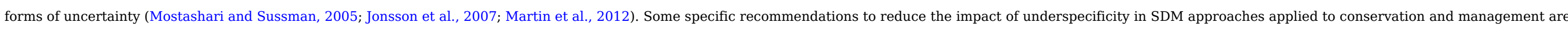
the following:

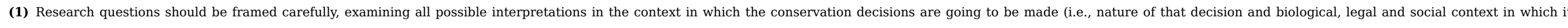
occurs; Runge, 2011). By doing so, "the right questions" can be identified and the research objectives and hypothesis can be structured and clarified with low levels of uncertainty (Kuhnert et al., 2010).

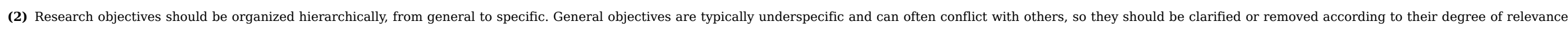

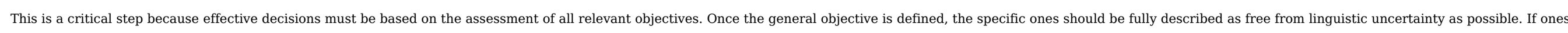




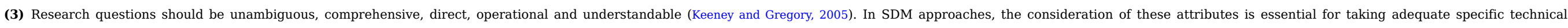
decisions that will enhance the value of subsequent analysis.

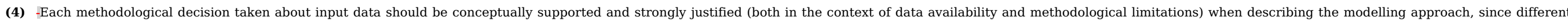
sequences of technical choices drive to large differences in model performance, complexity and spatial congruence across the model outputs.

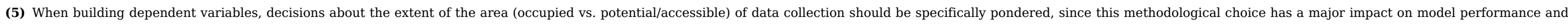
ecological interpretation of model outputs.

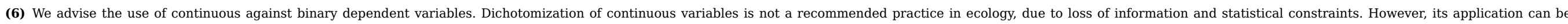
useful for explaining global ecological patterns when sample size is large and the threshold (cut-off point) is close to the optimal point (Fedorov et al., 2009).

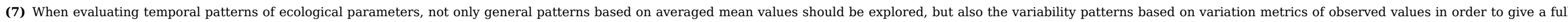
overview of the process under study.

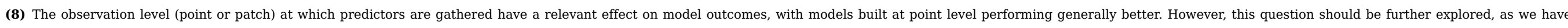
found differences in model performance depending on the area (occupied vs. potential/accessible) where predictors are collected.

\section{Acknowledgments}

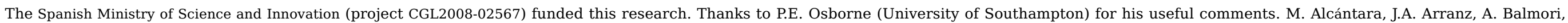

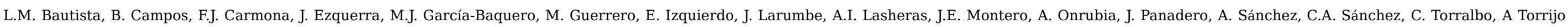

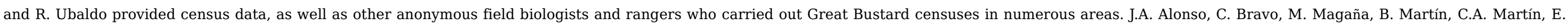

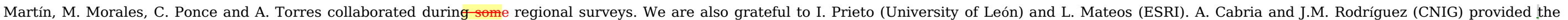
$5 \mathrm{~m}$-DEM and GIS databases.

This work was partially carried out in the Cantabrian Institute of Biodiversity (Mieres, Spain).

\section{Appendix 1.Appendix 1}




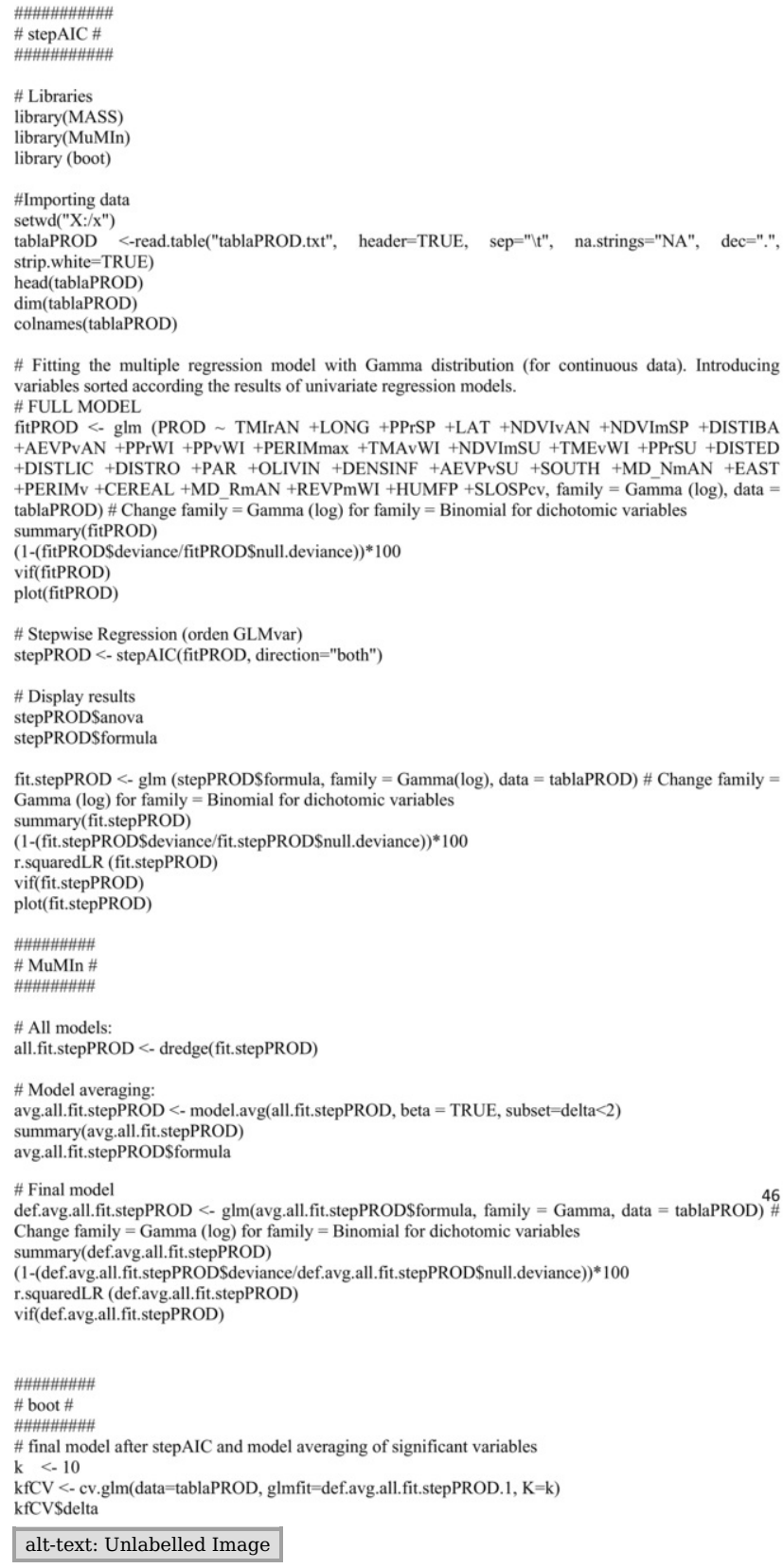

Appendix 2.Appendix 2. Averaged mean predicted values achieved for each database and distributional area of Great Bustard in Spain. Predicted values-Predictions obtained from databases 1 to 4 (Gamma GLM) can be interpreted as the breeding success value predicted as a function of the considered covariates, with values 
productivity values, ranging from 0 (0 chicks per 100 females) to 1 (100 chicks per 100 females). Predicted values achieved from databases 5 to 10 (binomial GLM) are the probability of having either a positive or a high breeding success, with probability values ranging from 0 to 1 . Databases 1 to 6 only apply to occupied areas, being not possible to extrapolate model predictions to potential and accessible ranges. Predicted values were extracted using an independent sample of 10,000 points randomly distributed across the study area

\begin{tabular}{|c|c|c|}
\hline \multicolumn{3}{|c|}{ alt-text: Unlabelled Table } \\
\hline & & Accessible area \\
\hline \multicolumn{3}{|c|}{ (a) Occupied area } \\
\hline Database 1 & 0.06 & \\
\hline Database 2 & 0.06 & \\
\hline Database 3 & 0.05 & \\
\hline Database 4 & 0.05 & \\
\hline Database 5 & 0.49 & \\
\hline Database 6 & 0.48 & \\
\hline \multicolumn{3}{|c|}{ (b) Potential/accessible area } \\
\hline Database 7 & 0.66 & \\
\hline Database 8 & 0.71 & \\
\hline Database 9 & 0.67 & \\
\hline Database 10 & 0.72 & \\
\hline
\end{tabular}

Appendix 3.Appendix 3. Spatial outputs achieved for each of the ten models developed to answer the target underspecific question 


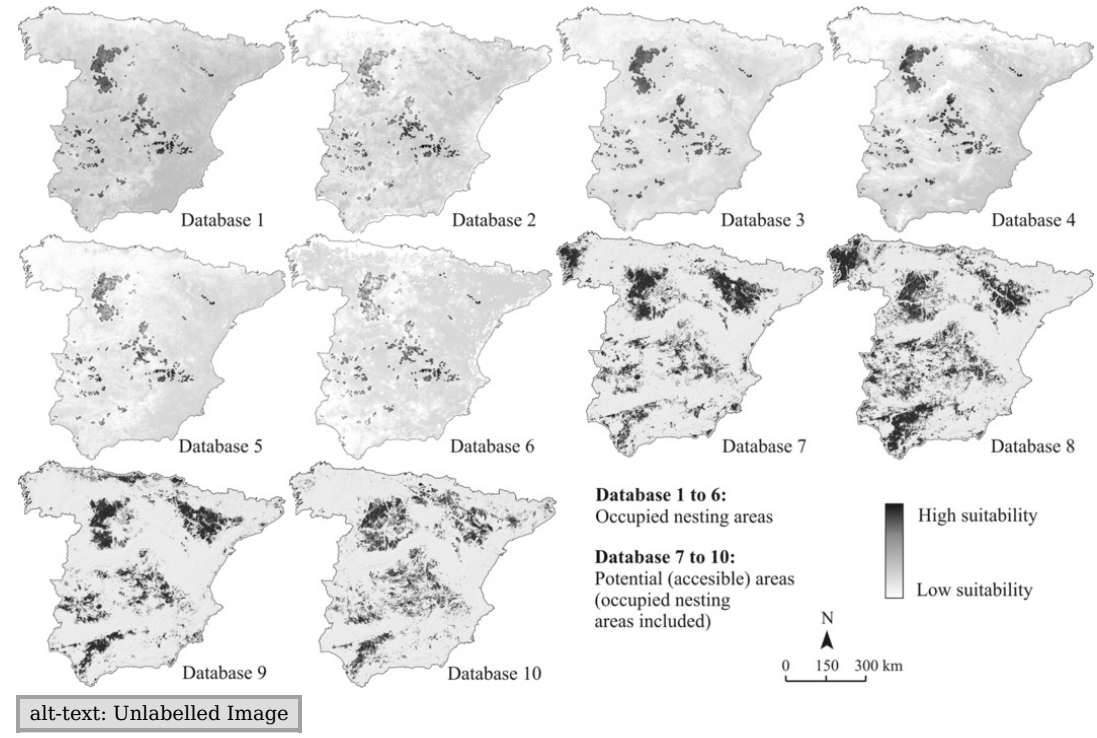

Appendix 4.Appendix 4. Pearson bivariate correlations among predicted continuous prediction values achieved from models calibrated in: (a) occupied area (models 1 to 6) and (b) potential/accessible area (models 7 to 10 ). Analyses were carried out using two separate samples-of 10,000 random points, separated at least $300 \mathrm{~m}$, being each sample distributed across either occupied or potential/accessible areas.

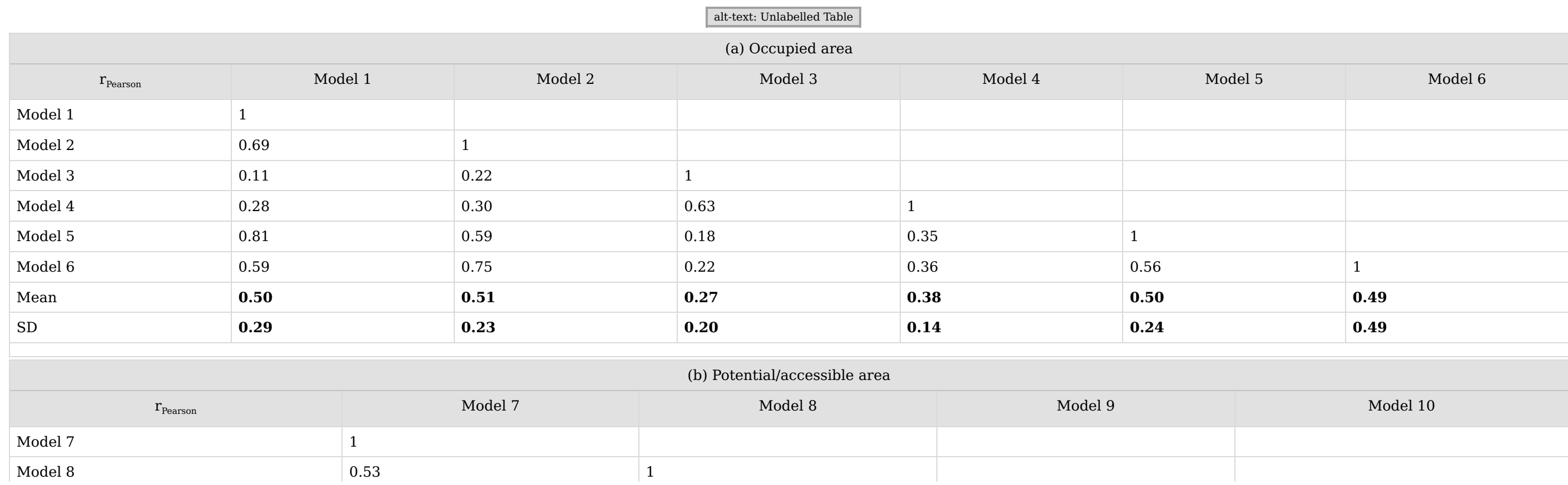




\begin{tabular}{|c|c|c|c|c|}
\hline Model 9 & 0.57 & 0.48 & 1 & \\
\hline Model 10 & 0.43 & 0.40 & 0.49 & 1 \\
\hline Mean & 0.51 & 0.48 & 0.51 & 0.44 \\
\hline SD & 0.08 & 0.09 & 0.05 & 0.05 \\
\hline
\end{tabular}

\section{References}

Alonso J.C. and Palacín C., The world status and population trends of the Great Bustard: 2010 update, Chinese Birds 1, 2010, 141-147.

Alonso J.C., Morales M.B. and Alonso J.A., Partial migration, and lek and nesting area fidelity in female great bustards, The Com 0

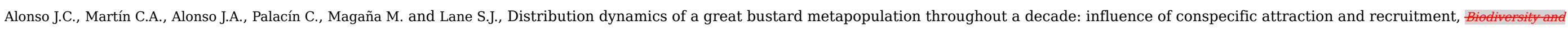
EonstionBiodivers. Conserv 13, 2004, 1659-1674.

Alonso J.C., Álvarez-Martínez J.M. and Palacín C., Leks in ground-displaying birds: hotspots or safe places?, 2011, 491-501.

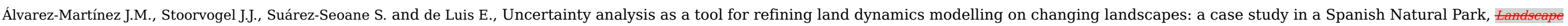
Ecolog Landsc. Ecol. 25, 2010, 1385-1404.

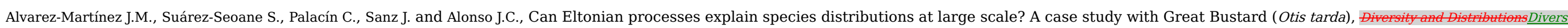
Distrib. 21, 2015, 123-138.

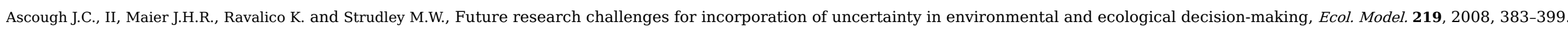

Austin M.P., Spatial prediction of species distribution: an interface between ecological theory and statistical modelling,

Austin M., Species distribution models and ecological theory: Aa critical assessment and some possible new approaches, Ecogical ModellingEcol. Model. 200, 2007, 1-19.

Barbraud C. and Weimerskirch H., Environmental conditions and breeding experience affect costs of reproduction in blue petrels, Ecology 86, 2005, 682-692.

Barry S. and Elith J., Error and uncertainty in habitat models, foumal of Applied Eeogy. Appl. Ecol. 43, 2006, 413-423.

Barton K., MuMIn: Multi-model Inference. R package Version 1.40.4, https://CRAN.R-project.org/package=MuMIn, 2018.

Beven K.J., On the concept of model structural error, water Seienee and Techology Water Sci. Technol. 52, 2005, 165-175.

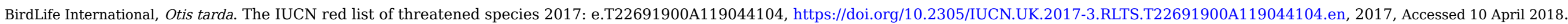

Borsuk M.E., Stow C.A. and Reckhow K.H., A Bayesian network of eutrophication models for synthesis, prediction, and uncertainty analysis, Ecological M/odellingEcol. Model. 173, 2004, 219-239.

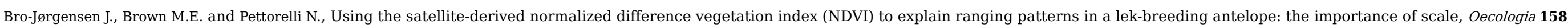
$2008,177-182$.

Bull J.W., Gordon A., Watson J.E. and Maron M., Seeking convergence on the key concepts in 'no net loss' policy, foumal of Applied EcologyJ. Appl. Ecol. 53, 2016 , 1686-1693.

Burgman M.A., Ferson S. and Akcakaya H.R., Risk Assessment in Conservation Biology, 1993, Chapman and Hall; London.

Burgman M.A., Lindenmayer D.B. and Elith J., Managing landscapes for conservation under uncertainty, Ecology 86, 2005, $2007-2017$.

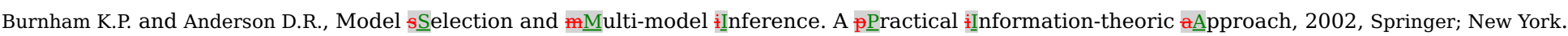




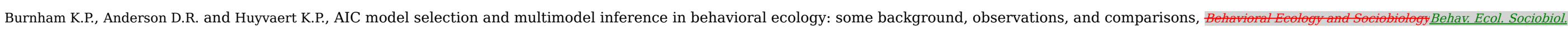
65, 2011, 23-35.

CNIG, Centro Nacional de Información Geográfica. Instituto Geográfico Nacional. Gobierno de España, http://www.cnig.es, 2012.

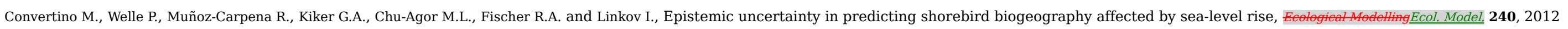
$1-15$.

Davison A.C. and Hinkley D.V., Bootstrap Methods and Their Application, 1997, Cambridge University Press.

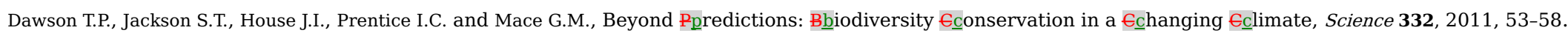

Elith J., Burgman M.A. and Regan H.M., Mapping epistemic uncertainties and vague concepts in predictions of species distribution, Ecological MadellingEcol. Model. 157, 2002, 313-329.

ESRI, ArcInfo desktop GIS 10.5, http://www.esri.com, 2016.

Fedorov V., Mannino F. and Zhang R., Consequences of dichotomization,

Franklin J., Moving beyond static species distribution models in support of conservation biogeography, Diversity and DistributionsDivers. Distrib. 16, 2010a, 321-330.

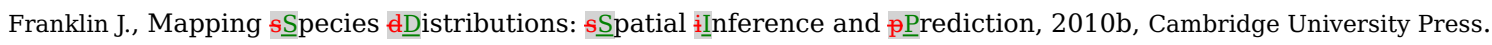

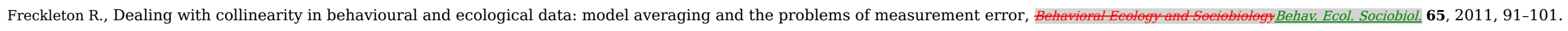

Graham M.H., Confronting multicollinearity in ecological multiple regression, Ecology 84, 2003, 2809-2815.

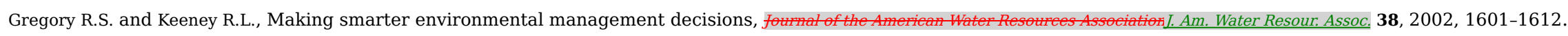

Guisan A., et al., Predicting species distributions for conservation decisions,

Harwood J. and Stokes K., Coping with uncertainty in ecological advice: lessons from fisheries, Trends Ecol. Evol. 18, 2003, 617-622.

Heinze G., Wallisch C. and Dunkler D., Variable selection-Aạ review and recommendations for the practicing statistician, Biometrieal foumaibiom. I. 60, $2018,431-449$.

Hirzel A.H. and Le Lay G., Habitat suitability modelling and niche theory, foumal of Applied EcologyJ. Appl. Ecol. 45, 2008, 1372-1381.

Jiménez-Valverde A., Lobo J.M. and Hortal J., Not as good as they seem: the importance of concepts in species distribution modelling, Điversity and distributionsDivers. Distrib. 14, 2008, 885-890.

Johnstone R.A., Models of reproductive skew: Aa review and synthesis, Ethology 106, 2000, 5-26.

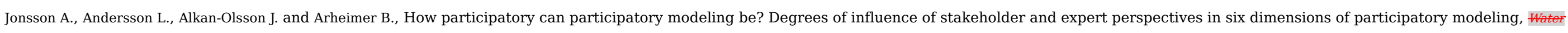

science and technology Water Sci. Technol. 56, 2007, 207-214.

Kearney M., Habitat, environment and niche: what are we modelling?, Oikos 115, 2006, 186-191.

Keeney R.L. and Gregory R.S., Selecting attributes to measure the achievement of objectives,

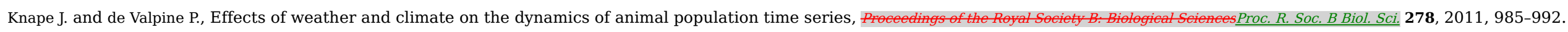

Kuhnert P.M., Martin T.G. and Griffiths S.P., A guide to eliciting and using expert knowledge in Bayesian ecological models, Ecology LettersEcol. Lett. 13, 2010, 900-914.

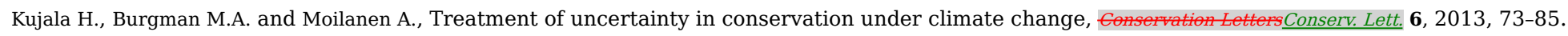

Lajoie G. and Vellend M., Understanding context dependence in the contribution of intraspecific variation to community trait-environment matching, Ecology 96, $2015,2912-2922$. 


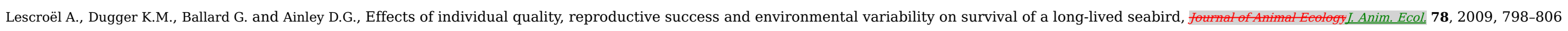
Lobo J.M., Jiménez-Valverde A. and Hortal J., The uncertain nature of absences and their importance in species distribution modelling, Ecography 33, 2010 , 103-114.

MacCallum R.C., Zhang S., Preacher K.J. and Rucker D.D., On the practice of dichotomization of quantitative variables, Psychologeal Methods Psychol. Methods 7, 2002 , 19-40.

Magaña M., Alonso J.C., Alonso J.A., Martín C.A., Martín B. and Palacín C., Great bustard (Otis tarda) nest locations in relation to leks, foumal of Ornithology J. Ornithol. 152, 2011, 541-548.

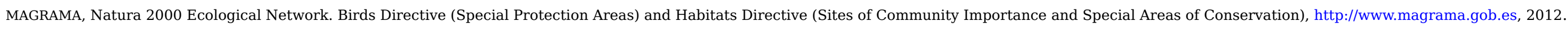

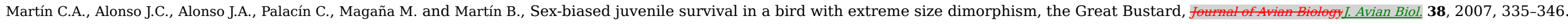

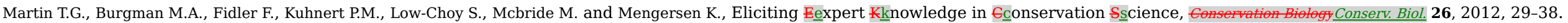

Martínez C., Distribution, density and productivity of great bustards in northwestern Spain: a regional approach, fournal of Ornithology I. Ornithol. 149, 2008, 507-514.

McCarthy M.A., Contending with uncertainty in conservation management decisions, Amats of the New York Academy of SeieneesAnn. N. Y. Acad. Sci. 1322, 2014 , 77-91.

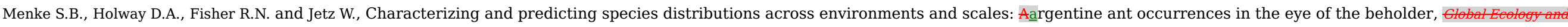
Bioghy Glob. Ecol. Biogeogr. 18, 2009, 50-63.

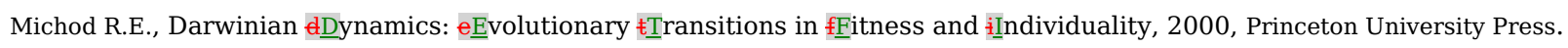

Milner-Gulland E.J. and Shea K., Embracing uncertainty in applied ecology, foumal of Applied Ecology I. Appl. Ecol. 54, 2017, $2063-2068$.

Morales M.B., Alonso J.C. and Alonso J.A., Annual productivity and individual female reproductive success in a Great Bustard population, Ibis 144, 2002, 293-300.

Mostashari A. and Sussman J., Stakeholder-assisted modelling and policy design process for environmental decision-making, J. Environ. Assess. Policy Manag. 7, 2005, 355-386.

Mundry R. and Numm C.L., Stepwise model fitting and statistical inference: turning noise into signal pollution, The American NaturalistAm. Nat. 173, 2009 , 119-123.

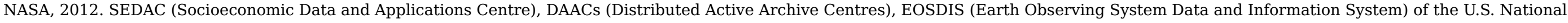

Aeronautics and Space Administration. Government of the United States of America.

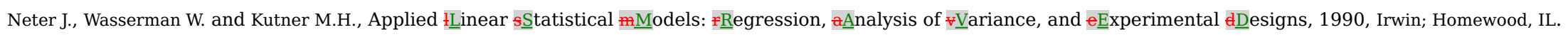

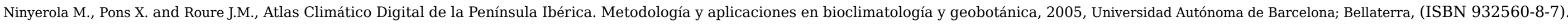

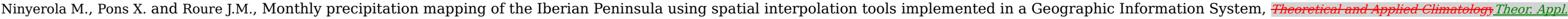

Climatol. 89, 2007, 195-209.

Openshaw S. and Taylor P.J., The modifiable areal unit problem, In: Wrigley and Bennett, (Eds.), Quantitative Geography: A British View, 1981, Routledge and Kegan Paul Ed; London, 60-69.

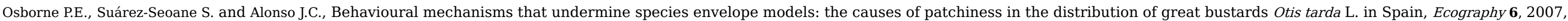
819-829.

Parejo D., Oro D. and Danchin E., Testing habitat copying in breeding habitat selection in a species adapted to variable environments, Ibis 148, 2006, $146-154$.

Pearman P.B., Guisan A., Broennimann O. and Randin C.F., Niche dynamics in space and time, Trends Ecol. Evol. 23, 2008, 149-158.

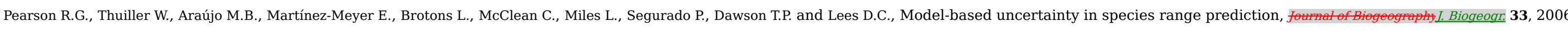
1704-1711. 
Peterson A.T., Uses and requirements of ecological niche models and related distributional models, 2006 , 59-72.

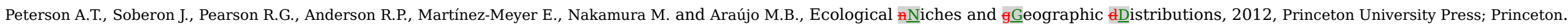

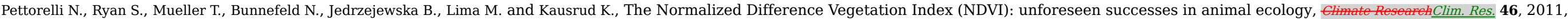
$15-27$.

Pinheiro J.C. and Bates D.M., Mixed-effects Models in S and SPLUS, 2000, Springer.

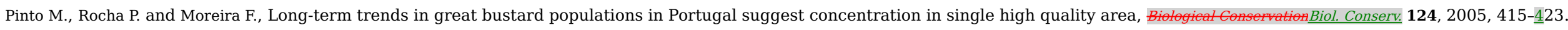

Polasky S., Carpenter S.R., Folke C. and Keeler B., Decision-making under great uncertainty: environmental management in an era of global change, Trends Ecol. Evol. 26, 2011, 398-404.

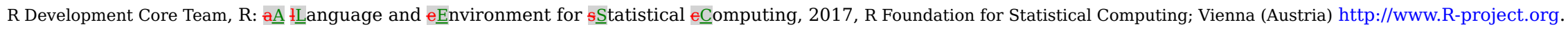

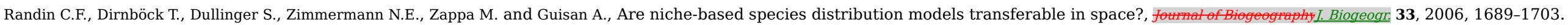

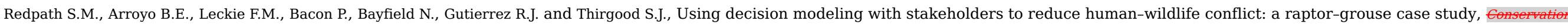

Biology Conserv. Biol. 18, 2004, 350-359.

Regan H.M., Colyvan M. and Burgman M.A., A taxonomy and treatment of uncertainty for ecology and conservation biology, Eeologieal ApplieationsEcol. Appl. 12, 2002, 618-628.

Rieucau G., Exploring the costs and benefits of social information use: an appraisal of current experimental evidence, Philos. Trans. R. Soc. B 366, 2011 , 949-957.

Rosema A., Verhees L. and van Putten E., European Energy and Water Balance Monitoring System. Scientific Report. Contract ENV4-CT97-0478, 2001, EU 4th Framework Program.

Royston P., Altman D.G. and Sauerbrei W., Dichotomizing continuous predictors in multiple regression: a bad idea, Statisties in MedieineStat. Med. 25, $2006,127-141$.

Runge M.C., An introduction to adaptive management for threatened and endangered species, J. Fish Wildl. Manag. 2, 2011, $220-233$.

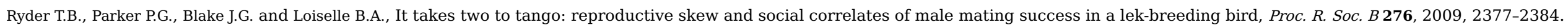

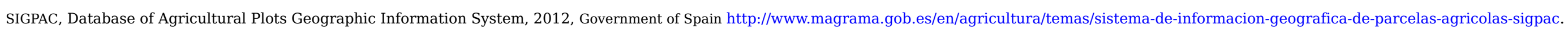
SIOSE, Land Cover Information System of Spain, 2012, Government of Spain http://www.siose.es/siose.

Soberon J., Grinnellian and Eltonian niches and geographic distributions of species, Eeofogy LettersEcol. Lett. 10, 2007, 1115-1123.

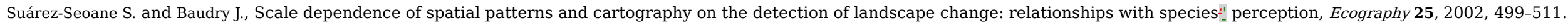

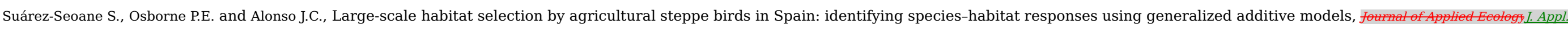
Ecol. 39, 2002, 755-771.

Suárez-Seoane S., Osborne P.E. and Rosema A., Can climate data from METEOSAT improve wildlife distribution models?, Ecography 27, 2004, 629-636.

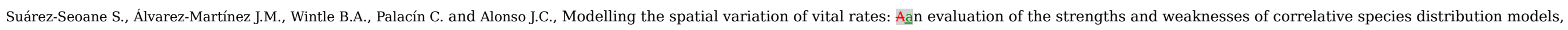

Diversity and DistributionsDivers. Distrib. 23, 2017, 841-853.

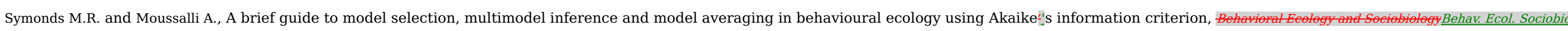

65, 2011, 13-21.

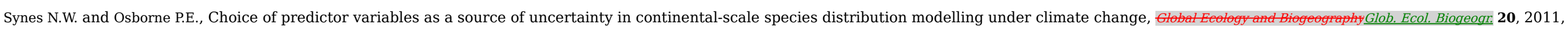


904-914.

Thuiller W., BIOMOD-optimizing predictions of species distributions and projecting potential future shifts under global change, Elobal Change Biology Glob. Chang. Biol 9, $2003,1353-\underline{13} 62$.

Thuiller W., Brotons L., Araújo M.B. and Lavorel S., Effects of restricting environmental range of data to project current and future species distributions, Ecography 27, 2004, 165-172.

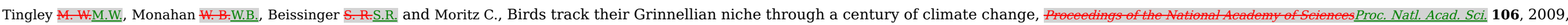
19637-19643.

Uusitalo L., Lehikoinen A., Helle I. and Myrberg K., An overview of methods to evaluate uncertainty of deterministic models in decision support, Environ. Model. Softw. 63, 2015, 24-31.

Venables W.N. and Ripley B.D., Modern Applied Statistics With S, 4th ed., 2002, Springer.

Warren D.L., In defense of "niche modelling", Trends Ecol. Evol. 27, 2012, 497-500.

Wong D., In: Warf and Hansen, (Eds.), The Modifiable Areal Unit Problem (MAUP). WorldMinds: Geographical Perspectives on 100 Problems, 2004 , Springer; Berlin, $571-575$.

Zuur A.F., Ieno E.N. and Elphick C.S., A protocol for data exploration to avoid common statistical problems, Methods in Eeology and EvolutionMethods Ecol. Evol. 1, 2010, 3-14.

\section{Highlights}

- Underspecificity drives to multiple methodological choices.

- It hampers the definition of conservation actions.

- It can be reduced in assisted modelling frameworks.

\section{Oueries and Answers}

Query:

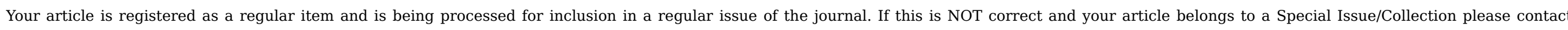
s.ananthakrishnan@elsevier.com immediately prior to returning your corrections.

\section{Answer: Yes}

Query:

Please confirm that given names and surnames have been identified correctly and are presented in the desired order, and please carefully verify the spelling of all authors' names.

Answer: Yes

Query:

The author names have been tagged as given names and surnames (surnames are highlighted in teal color). Please confirm if they have been identified correctly.

Answer: Yes

Query: 
Please check whether the designated corresponding author is correct, and amend if necessary.

Answer: It is correct, thank you.

Query:

Citation "Martin et al., 2007" has not been found in the reference list. Please supply full details for this reference.

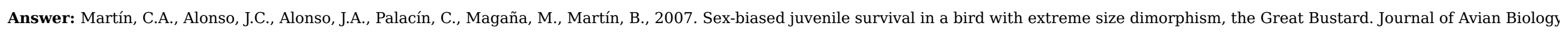
38, 335-346

Query:

Citation "Alvarez-Martínez et al., 2014" has not been found in the reference list. Please supply full details for this reference.

Answer: Please change this citation by "Alvarez-Martínez et al., 2015", which it is included in the reference list.

Query:

Citation "Soberon and Peterson, 2005" has not been found in the reference list. Please supply full details for this reference.

Answer: Soberon, J., Peterson, A.T., 2005. Interpretation of models of fundamental ecological niches and species' distributional areas. Biodiversity Informatics 2, 1-10

Query:

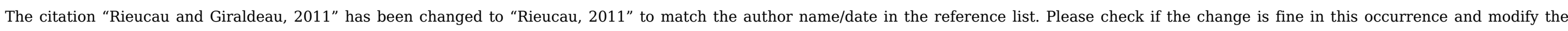
subsequent occurrences, if necessary.

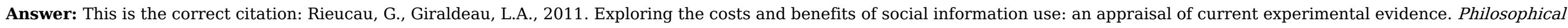
Transactions of the Royal Society of London B: Biological Sciences 366 (1567), 949-957.

\section{Query:}

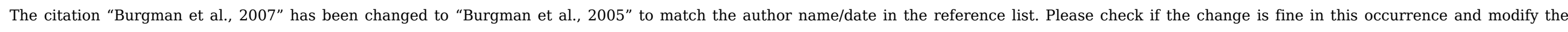
subsequent occurrences, if necessary.

\section{Answer: Ok}

Query:

Have we correctly interpreted the following funding source(s) and country names you cited in your article: "Spanish Ministry of Science and Innovation, Spain".

Answer: Yes

Query:

Please check the layout and presentation of Appendix 2 if correct.

Answer: Yes, but we have made some changes on the legend

Query:

Please check the layout and presentation of Appendix 4 if correct. 
Answer: Yes, but we have made some changes on the legend

Query:

Please provide a definition for the significance of bold in the Appendix 4.

Answer: Ok, done 